\title{
Corrigendum
}

Cold Spring Harb Protoc 2016; doi: 10.1101/pdb.prot090068

\section{Corrigendum: Real-Time Protein-Fragment Complementation Assays for Studying Temporal, Spatial, and Spatiotemporal Dynamics of Protein-Protein Interactions in Living Cells}

Mohan Malleshaiah, Emmanuelle Tchekanda, and Stephen W. Michnick

When this protocol was first published, the concentrations for the reagents in the recipe entitled "Amino Acid Mix (10X)" were expressed as $\mathrm{g} / \mathrm{mL}$, but they should have been expressed as $\mathrm{g} / \mathrm{L}$. The authors apologize for this error. The HTML version of the recipe (doi: 10.1101/pdb.rec090308) has been corrected, as has the current PDF version of the protocol. A corrected version of the recipe is also included below.

Amino Acid Mix (10x)

Amino acid or nucleobase

Concentration $(10 \times)$

Adenine sulfate

$0.4 \mathrm{~g} / \mathrm{L}$

Uracil

$0.2 \mathrm{~g} / \mathrm{L}$

L-Tryptophan

$0.4 \mathrm{~g} / \mathrm{L}$

L-Histidine hydrochloride

$0.2 \mathrm{~g} / \mathrm{L}$

L-Arginine hydrochloride

$0.2 \mathrm{~g} / \mathrm{L}$

L-Tyrosine

$0.3 \mathrm{~g} / \mathrm{L}$

L-Leucine

$0.6 \mathrm{~g} / \mathrm{L}$

L-Lysine hydrochloride

$0.3 \mathrm{~g} / \mathrm{L}$

L-Phenylalanine

$0.5 \mathrm{~g} / \mathrm{L}$

L-Glutamic acid

$1.0 \mathrm{~g} / \mathrm{L}$

L-Asparagine

$1.0 \mathrm{~g} / \mathrm{L}$

L-Valine

$1.5 \mathrm{~g} / \mathrm{L}$

L-Threonine

$2.0 \mathrm{~g} / \mathrm{L}$

L-Serine

$3.75 \mathrm{~g} / \mathrm{L}$

L-Methionine

$0.2 \mathrm{~g} / \mathrm{L}$

Dissolve the amino acids from the list above (except those to be excluded from any dropout media) in distilled $\mathrm{H}_{2} \mathrm{O}$. Filter-sterilize, store at $4^{\circ} \mathrm{C}$, and protect from light.

(C) 2022 Cold Spring Harbor Laboratory Press

Cite this corrigendum as Cold Spring Harb Protoc; doi:10.1101/pdb.corr107815 


\section{Corrigendum: Real-Time Protein-Fragment Complementation Assays for Studying Temporal, Spatial, and Spatiotemporal Dynamics of Protein-Protein Interactions in Living Cells}

Mohan Malleshaiah, Emmanuelle Tchekanda and Stephen W. Michnick

Cold Spring Harb Protoc; doi: 10.1101/pdb.corr107815

\begin{aligned} & \hline $\begin{array}{r}\text { Email Alerting } \\ \text { Service }\end{array}$ Receive free email alerts when new articles cite this article - click here. \\ & \hline $\begin{array}{c}\text { Subject } \\ \text { Categories }\end{array}$ Browse articles on similar topics from Cold Spring Harbor Protocols. \\ & \hline\end{aligned}

